\title{
Advanced Maternal Age: Adverse Outcomes of Pregnancy, A Meta-Analysis
}

\section{Idade Materna Avançada: Desfechos Adversos da Gravidez, Uma Meta-Análise}

\author{
Rosa Lomelino PINHEIRO $\rrbracket^{1}$, Ana Luísa AREIA ${ }^{1}$, Anabela MOTA PINTO ${ }^{2,3}$, Helena DONATO \\ Acta Med Port 2019 Mar;32(3):219-226 - https://doi.org/10.20344/amp.11057
}

\section{ABSTRACT}

Introduction: The risks of pregnancy in women of advanced maternal age are not consensual amongst studies. The aim of this metaanalysis was to determine whether women of advanced maternal age ( $\geq 35$ years old) had worse obstetrical and perinatal outcomes than non- advanced maternal age women (20 - 34 years old) in singleton, naturally-conceived pregnancies.

Material and Methods: We searched PubMed/ MEDLINE, IndexRMP and the Cochrane Database of Systematic Reviews. Ten studies were included according to the following criteria: population of $>1000$ nulliparous and/or multiparous women with singleton gestations who did not undergo any type of infertility treatment. Using Review Manager v. 5.3, two meta-analysis were performed: one comparing the outcomes of 20 - 34-year-old vs 35 - 40-year-old women, and another comparing the outcomes of 35 - 40-year-old women vs > 40-year-old women.

Results: Women aged 35 - 40 years old were more likely to have $>12$ years of education than 20 - 34 years old and $>40$ years old women. Advanced maternal age women ( $35-40$ and $>40$ years old) were more likely to be overweight and having gestational diabetes and gestational hypertension. They were also more likely to undergo induced labour and elective caesarean deliveries. Furthermore, they had worse perinatal outcomes such as preterm delivery, low birthweight babies, higher rates of Neonatal Intensive Care Unit admission and worse Apgar scores. Advanced maternal age women had higher rates of perinatal mortality and stillbirth.

Discussion: Most authors present similar results to our study. Although the majority of adverse outcomes can be explained through the physio-pathological changes regarding the female reproductive apparatus that come with aging and its inherent comorbidities, according to the existing literature advanced maternal age can be an independent risk factor per se. In older pregnant women without comorbidities such as gestational hypertension or diabetes there are still worse obstetric and perinatal outcomes, which indicate that advanced maternal age is an independent strong risk factor alone.

Conclusion: Advanced maternal age women are at a higher risk of adverse obstetrical and perinatal outcomes. In both comparisons, worse outcomes were more prevalent in the older group, suggesting that poorer outcomes are more prevalent with increasing age.

Keywords: Maternal Age; Pregnancy Complications; Pregnancy Outcome

\section{RESUMO}

Introdução: Não há consenso na literatura sobre os riscos da gravidez em mulheres com idade materna avançada. O objetivo desta meta-análise consistiu em determinar se as mulheres com idade materna avançada $(\geq 35)$ tiveram piores desfechos obstétricos e perinatais, comparativamente com as mulheres não-idade materna avançada (20 - 34 anos), em gestações de feto único e por conceção natural.

Material e Métodos: A pesquisa bibliográfica foi feita na PubMed/MEDLINE, IndexRMP e na Cochrane Database of Systematic Reviews. Foram incluídos dez estudos segundo os seguintes critérios: população-estudo $>1000$ mulheres, nulíparas e/ou multíparas, com gestações de feto único sem recurso a tecnologias de reprodução medicamente assistida. Duas meta-análises foram feitas com o programa Review Manager v. 5.3: uma comparando os desfechos da gravidez do grupo 20 - 34 anos com o grupo 35 - 40 anos e outra comparando os grupos de idades 35 - 40 e $>40$ anos.

Resultados: As mulheres com 35 - 40 anos tiveram mais probabilidade de ter $>12$ anos de escolaridade, comparativamente ao grupo 20 - 34 e $>40$ anos. Mulheres com idade materna avançada (35 - 40 e $>40$ anos) tiveram maior probabilidade de ter excesso de peso e comorbilidades como diabetes gestacional e hipertensão gestacional. Tiveram também maior frequência de partos induzidos e de cesarianas eletivas. As mulheres mais velhas tiveram mais partos pré-termo e recém-nascidos com baixo peso. Os bebés das mães com idade materna avançada foram mais vezes admitidos na Unidade de Cuidados Intensivos Neonatais e tiveram piores índices de Apgar. De igual forma, as mulheres com idade materna avançada tiveram maiores taxas de mortalidade perinatal e morte in utero. Discussão: A maioria dos autores descreve resultados semelhantes àqueles que estão descritos na meta-análise. Embora os resultados desfavoráveis sejam em grande parte explicados pela fisiopatologia do envelhecimento do sistema reprodutor da mulher e comorbilidades inerentes ao avançar da idade, a bibliografia admite a idade materna avançada um fator de risco per se. Mesmo em mulheres com idade materna avançada sem comorbilidades como diabetes ou hipertensão gestacional, esta acaba por ser um fator de risco independente e significativo para desfechos adversos.

Conclusão: Mulheres com idade materna avançada têm um maior risco de desfechos obstétricos e perinatais adversos. Em ambas as comparações os piores desfechos foram mais prevalentes no grupo de mulheres com maior idade, sugerindo maior expressão com o avançar da idade.

Palavras-chave: Complicações na Gravidez; Idade Materna; Resultado da Gravidez

1. Obstetrics Unit A. Centro Hospitalar e Universitário de Coimbra. Coimbra. Portugal.

2. Laboratory of General Pathology. Faculty of Medicine. University of Coimbra. Coimbra. Portugal.

3. CIMAGO - Centre of Investigation of Environment, Genetics and Oncobiology. Coimbra. Portugal.

4. Documentation Service. Centro Hospitalar e Universitário de Coimbra. Coimbra. Portugal.

$\triangle$ Autor correspondente: Rosa Lomelino Pinheiro. rosafigueirapinheiro@gmail.com

Recebido: 15 de julho de 2018 - Aceite: 29 de dezembro de 2018 | Copyright @ Ordem dos Médicos 2019 


\section{INTRODUCTION}

Women are postponing childbearing to their late $35 \mathrm{~s}$, 40 s and beyond almost all around the world. ${ }^{1-7}$ It is consensual that the desire to build successful careers and have equal opportunities in the job market, as well as attaining financial stability, are major concerns to most women nowadays. ${ }^{4,8}$ In less resourced countries, childbearing is more common amongst multiparous older women due to ineffective family planning methods and favourable cultural disposition towards a large family size..$^{9,10}$

For most authors, the definition of advanced maternal age (AMA) is 35 years and above. ${ }^{11-14}$ However, in medical literature AMA is often defined as age over 40 years. 10,15-17

Most studies conclude that pregnancy at advanced age is seldom without risks. However, those conclusions based on individual obstetrical or perinatal adverse outcomes lack consensus. Some authors describe specific events that do not differ between AMA and non-AMA, such as preterm birth, low birthweight, small for gestational age, and perinatal mortality. ${ }^{5,11-13,15,18}$

When hypothesizing the reasons why AMA women have worse outcomes in their pregnancies, there are multiple theories. Some claim age alone is not a risk factor. ${ }^{11,13}$ According to Aldrighi et al, ${ }^{19}$ adequate follow-up during the prenatal period and suitable care during childbirth make maternal and perinatal prognoses similar to those of younger pregnant women. Li et a ${ }^{20}$ studied a group of low-risk pregnant women and also found more negative outcomes in AMA women. This led us to believe that neither does preexisting disease fully explain why older women have worse pregnancy outcomes. ${ }^{4,8,16}$

The purpose of this study was to perform a systematic review and meta-analysis on obstetrical and perinatal outcomes of singleton gestations at AMA (35 - 40 and $>40$ years old), compared to non-AMA (20 - 34 years old). Furthermore, we put forward an explanation as to why conclusions vary among studies.

\section{MATERIAL AND METHODS}

The research was performed using PubMed/MEDLINE and the Cochrane Database of Systematic Reviews. We limited our research to published articles available between January 2006 and March 2017 in English, Portuguese, Spanish, Italian and French. References of relevant studies and recent reviews were hand-searched for additional publications.

The search terms were 'advanced maternal age', 'advanced maternal age' AND 'pregnancy outcomes', AND 'perinatal outcomes', 'Pregnancy over 35 years old', 'Pregnancy over 40 years old', 'Delayed childbearing'.

The predefined inclusion criteria were: studies with a study population of over 1000 women, including cohort studies, cross-sectional studies, systematic reviews and meta-analysis; from any country; singleton gestations.

Advanced maternal age (study group) was defined as women 35 years and older, but studies considering the AMA group as women over 40 years were also considered.
Exclusion criteria were papers including women who underwent any type of assisted reproductive technology and articles focusing solely on congenital abnormalities. Moreover, for our meta-analysis, group studies including women with large age intervals among them $(20-30,>40$ years apart) were also dismissed. The reason to do so is that age and its effects act like a continuum rather than a threshold. ${ }^{20-22}$

Two of the authors assessed the risk of bias for individual studies by verifying methodological strategies and definitions of inclusion criteria and outcomes. The quality of the studies included was assessed via the Methodological Index for Non-Randomized Studies, ${ }^{23}$ using the following criteria: (1) clearly stated aim, (2) inclusion of consecutive patients, (3) unbiased assessment of the study endpoint, (4) contemporary groups, (5) baseline equivalence of groups and (6) adequate statistical analysis.

Ten studies met all the criteria defined above and these were carefully analysed by two of the authors to determine whether they would be appropriate for a combined analysis. Any discrepancies were resolved through discussion.

Finally, upon reviewing the articles, data were extracted by one of the authors.

The numbers were automatically compared and analysed using the Review Manager version 5.3. Two analyses were performed: the first comparing the 20 - 34 and 35 - 40 age groups and the second comparing the $35-40$ and $>40$ age groups.

\section{Variable definition}

Gestational hypertension included preeclampsia. Preterm birth was defined as before 37 weeks of gestation. Birthweight was categorized as follows: very low birthweight $(<1500 \mathrm{~g})$, low birthweight $(1500-2500 \mathrm{~g})$ and macrosomia (>4000 g). Small for gestational age was defined as birthweight below the $10^{\text {th }}$ percentile of the sex-specific curve of birthweight for gestational age. ${ }^{24}$ Maternal nearmiss included women who nearly died but survived a complication during pregnancy, childbirth, or within 42 days of termination of pregnancy. Maternal death was the death of a woman while pregnant or within 42 days of termination of pregnancy, according to the World Health Organization. ${ }^{25}$ Perinatal mortality was defined as stillbirth and neonatal death (death before 28 completed days after birth). Stillbirth was defined as intrauterine death of a child after 22 weeks of gestation or weighing $\geq 500 \mathrm{~g}$.

Statistical heterogeneity was measured using the $\mathrm{I}^{2}$ statistic. The fixed-effects model was used in this meta-analysis if there was no evidence of heterogeneity $\left(I^{2} \leq 40 \%\right)$; otherwise, the Mantel-Haenszel model for random-effects was used. We calculated odds ratio (OR) and 95\% confidence intervals $(95 \% \mathrm{Cl})$ for the outcomes.

Potential publication biases were assessed graphically by using a funnel plot of the 'preterm birth', 'elective cesarean section' and 'maternal death' outcomes. No adjustment for risk estimates was made. 
This meta-analysis was performed in compliance with the PRISMA recommendations. ${ }^{26}$

\section{RESULTS}

A total of 253 studies were identified. After screening abstracts, 171 were considered ineligible because either they included women with multiple pregnancy and/or assisted reproductive technology, or data was not reported for this variable (Fig. 1). Eighty-two full-text articles were fully read and 30 dismissed due to either one of the following reasons: different age groups, or irrelevant topic. Finally, 52 studies were excluded as data had been obtained through questionnaires or were not retrievable. Ten studies met all the criteria defined for our meta-analysis and were rated for quality according to the Methodological Index for Non-Randomized Studies ${ }^{23}$; all studies had 'low risk of bias'. The risk of publication bias was assessed by using a funnel plot of three outcomes; the symmetrical plots suggested no publication bias. The study characteristics are presented in Table 1.

Education data were available in six out of the 10 studies. The 35 - 40 YO age group included more women with $>12$ years of education than the $20-34$ YO (OR 1.44; 95\% $\mathrm{Cl} ; 1.32-1.57, \mathrm{I}^{2}=94 \%$ ) and the $>40 \mathrm{YO}$ age groups (OR $\left.0.91 ; 95 \% \mathrm{Cl} ; 0.83-1.00, l^{2}=83 \%\right)$. In contrast, women aged 20 - 34 YO (OR 0.71; 95\% Cl; $0.66-0.76, l^{2}=93 \%$ ), and > 40 YO (OR 1.07; 95\% Cl; $0.95-1.21, l^{2}=92 \%$ ) had more often $\leq 12$ years of education.

Five out of the 10 studies were available for $\mathrm{BMI} \geq 25$ analysis, showing that AMA women [35 - 40 YO (OR 1.17; $95 \% \mathrm{Cl} ; 1.06-1.30, I^{2}=98 \%$ ) and > 40 YO (OR 1.09; $95 \%$ $\mathrm{Cl} ; 1.02-1.17, \mathrm{I}^{2}=77 \%$ )] were more likely to be overweight.

Two and three studies had data on chronic and gestational hypertension, respectively. AMA women [35 - $40 \mathrm{YO}$ (OR 1.82; 95\% Cl; 1.63 - 2.02, $I^{2}=53 \%$ ), (OR 1.06; 95\% Cl; $\left.0.95-1.18, l^{2}=90 \%\right)$, and $>40$ YO (OR 1.65; 95\% Cl; 1.52 - $\left.1.80, I^{2}=0 \%\right),\left(\right.$ OR $\left.\left.1.30 ; 95 \% \mathrm{Cl} ; 1.23-1.37, l^{2}=7 \%\right)\right]$
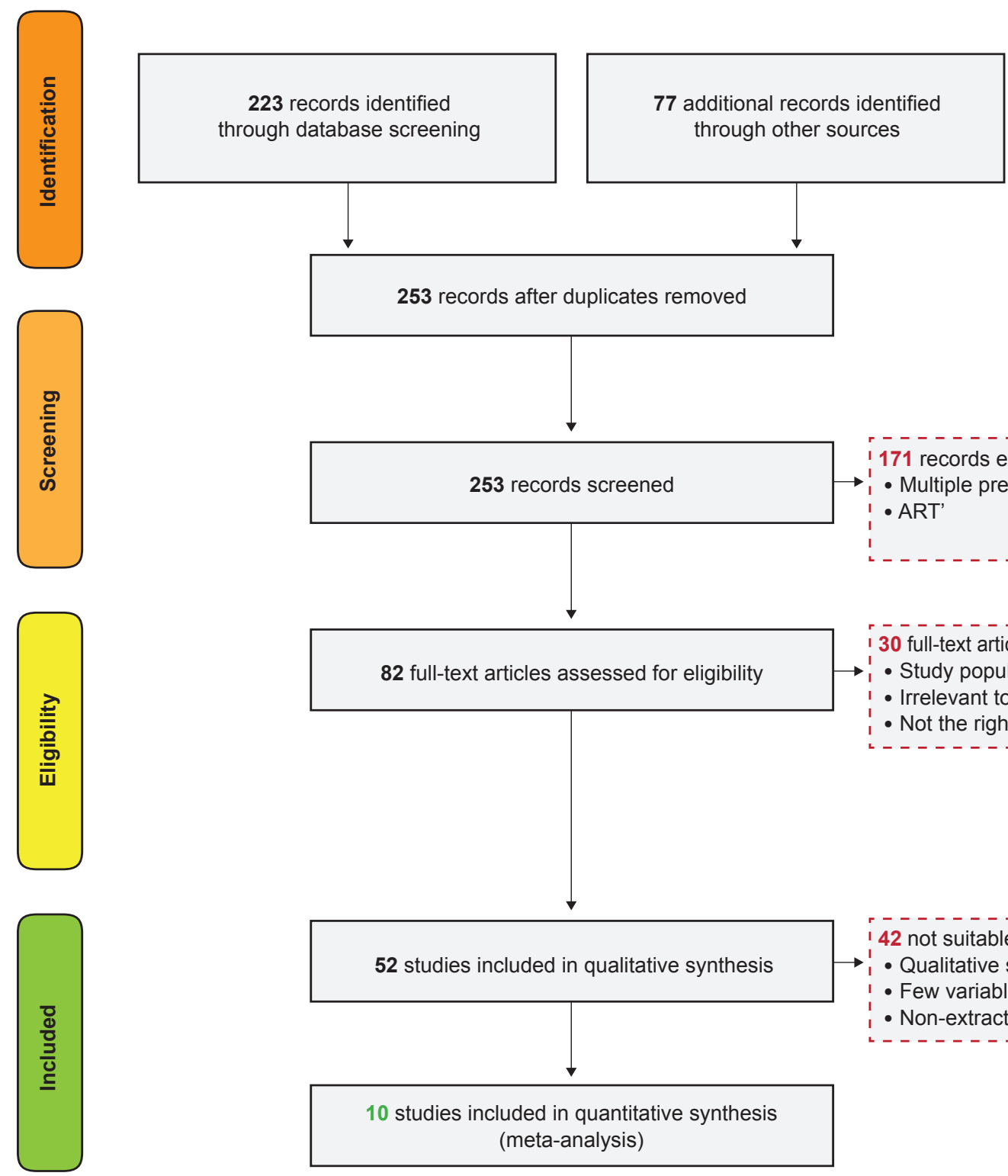

42 not suitable for the meta-analysis

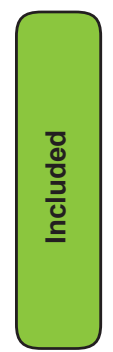

- Qualitative studies

- Few variables/ low-risk women

- Non-extractable data

Figure 1 - Flow diagram of studies identified 


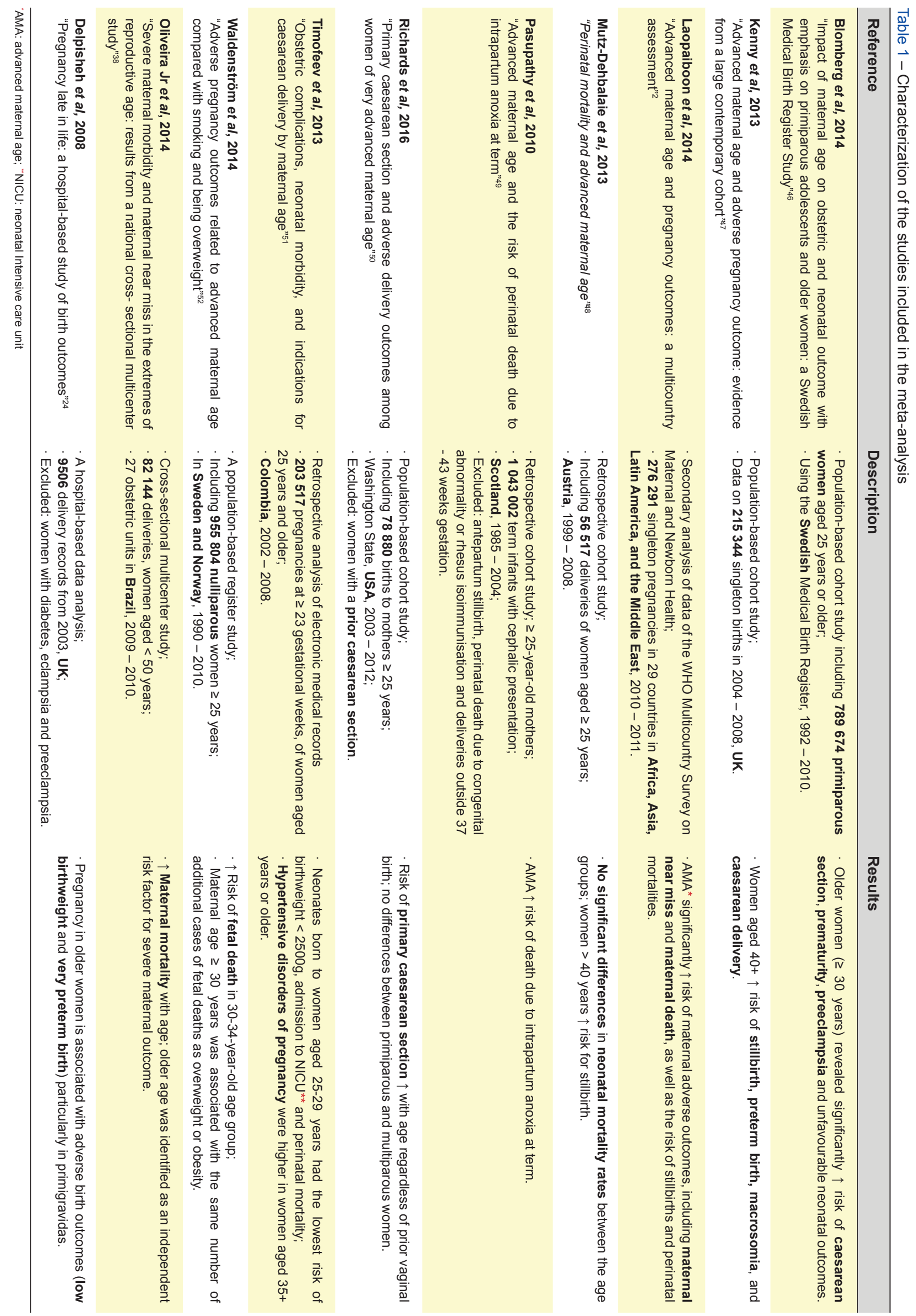


Odds ratio

$\mathrm{M}-\mathrm{H}$, fixed, $95 \% \mathrm{Cl}$

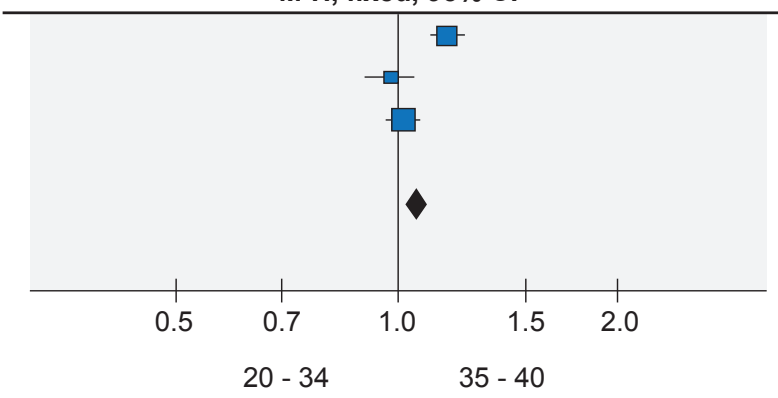

Figure 2 - Gestational hypertension

had more comorbidities (Fig. 2). Again, women in the older groups were more likely to have pre-gestational [35 - $40 \mathrm{YO}$ (OR 1.89; 95\% Cl; $1.59-2.25, I^{2}=67 \%$ ), and > 40 YO (OR $\left.\left.1.26 ; 95 \% \mathrm{Cl} ; 1.13-1.40, I^{2}=17 \%\right)\right]$ and gestational diabetes [35 - 40 YO (OR 1.81; 95\% Cl; $1.39-2.37, l^{2}=98 \%$ ), and $>40$ YO (OR 1.38; $\left.95 \% \mathrm{Cl} ; 1.31-1.46, l^{2}=0 \%\right)$ ], as two studies showed.

Four studies included data on labour and six on elective CS; women aged 20 - 34 YO (OR 0.71; 95\% Cl; 0.53 - 0.95, $I^{2}=100 \%$ ) underwent more spontaneous labours. Women aged 35 - 40 YO (OR 1.09; 95\% Cl; 0.85 - 1.39, $l^{2}=100 \%$ ), (OR 1.96; 95\% Cl; $\left.1.54-2.50, l^{2}=100 \%\right)$ and $>40$ YO (OR $1.11 ; 95 \% \mathrm{Cl} ; 0.97-1.27, l^{2}=96 \%$ ), (OR 1.42; 95\% Cl; 1.22 $-1.67, I^{2}=97 \%$ ) had more induced labours and elective CS.

Regarding maternal morbidity and mortality, two studies were available. AMA women were at a higher risk of maternal near-miss [35 - 40 YO (OR 2.02; 95\% Cl; $1.80-2.26, l^{2}$ $=0 \%$ ), and > 40 YO (OR 1.76; 95\% Cl; $1.47-2.11, l^{2}=0 \%$ ] and maternal death [35 - 40 YO (OR 1.61; 95\% Cl; 1.21 $\left.2.13, I^{2}=0 \%\right)$ and > 40 YO (OR 1.67; 95\% Cl; 1.07 - 2.63, $\left.\left.I^{2}=0 \%\right)\right]$

Seven studies were available for preterm birth analysis. AMA women had more preterm deliveries than younger women [35 - 40 YO (OR 1.21; 95\% Cl; $1.16-1.27, l^{2}=$ $88 \%$ ), and > 40 YO (OR 1.18; 95\% Cl; $1.10-1.27, l^{2}=$ $74 \%)$ ] (Fig. 3). Data on birthweight were available in three out of the 10 studies. AMA women had more babies with

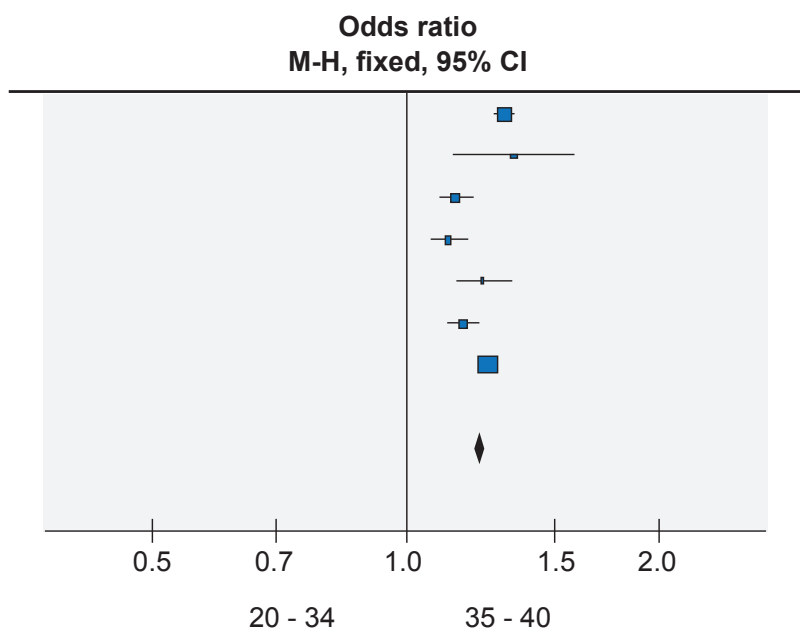

Odds ratio

$\mathrm{M}-\mathrm{H}$, fixed, $95 \% \mathrm{Cl}$

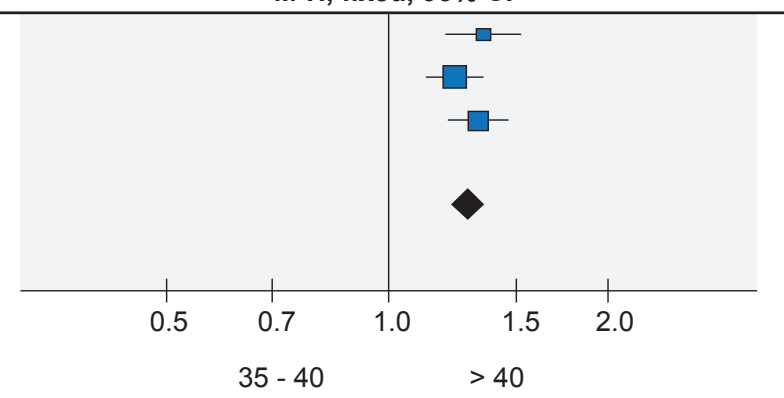

very low [35 - 40 YO (OR 1.25; 95\% Cl; $\left.1.17-1.33, I^{2}=0 \%\right)$ and > 40 YO (OR 1.19; 95\% Cl; $\left.1.10-1.29, l^{2}=0 \%\right)$ ] and low birthweight [35 - 40 YO (OR 1.10; 95\% Cl; $1.05-1.15$, $\left.l^{2}=29 \%\right)$ and $>40$ YO (OR 1.40; $95 \% \mathrm{Cl} ; 1.19-1.64, l^{2}=$ $41 \%)]$. The $35-40 \mathrm{YO}$ age group had more macrosomic babies (OR 1.17; 95\% Cl; $1.02-1.33, l^{2}=94 \%$ ) compared to the 20 - $34 \mathrm{YO}$ age group. The difference between 35 - 40 $v s>40$ YO was not statistically significant $(p=0.84)$. Two studies included data on small for gestational age (SGA) infants. Babies born to 20 - 34 YO (OR 0.78; 95\% Cl; 0.74 $0.81, I^{2}=0 \%$ ) and > 40-year-old mothers (OR 1.54; 95\% Cl; $0.69-3.40, l^{2}=75 \%$ ) were more likely to be SGA.

Data on Neonatal Intensive Care Unit (NICU) admissions and Apgar scores were available in two and four out of 10 studies, respectively. Newborns of AMA women had more NICU admissions [35 - 40 YO (OR 1.13; 95\% Cl; 1.09 - 1.18, $l^{2}=47 \%$ ), and > 40 YO (OR 1.20; 95\% Cl; 1.13 $\left.1.27, I^{2}=0 \%\right)$ and Apgar scores $<7$ at 5 minutes (35- 40 YO (OR 1.26; 95\% Cl; $1.09-1.47, l^{2}=95 \%$ ), and $>40$ YO (OR 1.17; 95\% Cl; $1.04-1.32, I^{2}=66 \%$ )]. Regarding perinatal mortality and stillbirth, data were available in six and five out of 10 studies, respectively. AMA women had higher rates of perinatal mortality [35 - $40 \mathrm{YO}(\mathrm{OR} 1.19 ; 95 \% \mathrm{Cl}$; $1.05-1.34, I^{2}=74 \%$ ), and > 40 YO (OR $1.40 ; 95 \% \mathrm{Cl} ; 1.17$ $\left.-1.68, l^{2}=55 \%\right)$ ] and stillbirth [35 - 40 YO (OR 1.55; 95\% $\left.\mathrm{Cl} ; 1.35-1.77, \mathrm{I}^{2}=83 \%\right)$, and > $40 \mathrm{YO}(\mathrm{OR} 1.33 ; 95 \% \mathrm{Cl}$; $\left.1.21-1.46, l^{2}=32 \%\right)$ ] (Fig.4).

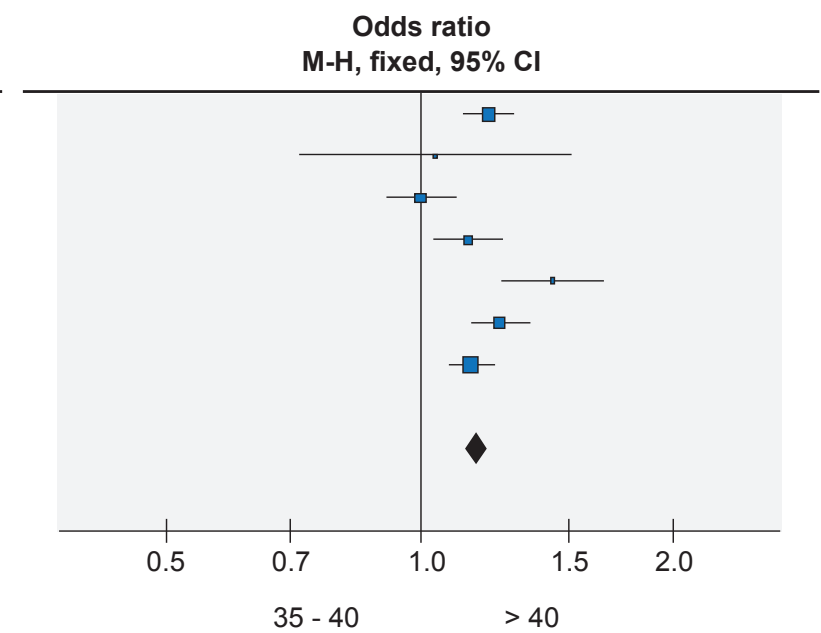

Figure 3 - Preterm birth $(<37$ weeks $)$ 
Odds ratio

$\mathrm{M}-\mathrm{H}$, fixed, $95 \% \mathrm{Cl}$

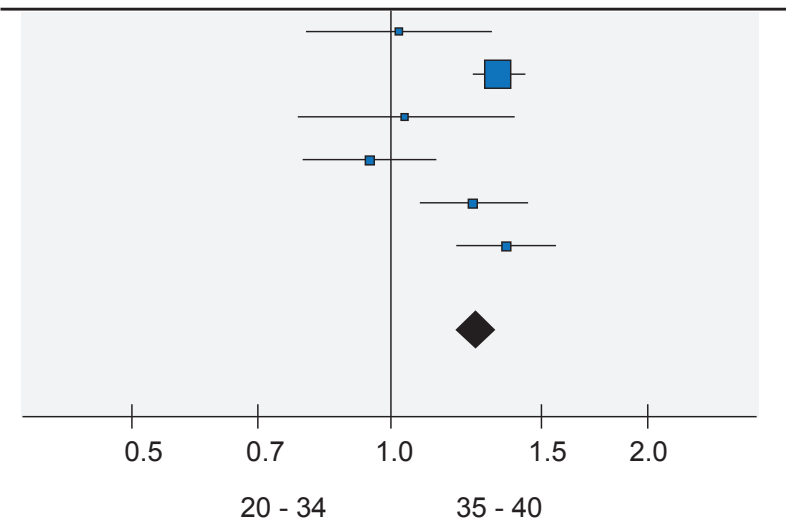

Figure 4 - Perinatal mortality

\section{DISCUSSION}

Higher rates of stillbirth in older women is a common finding among other published studies, ${ }^{21,27,28}$ irrespective of parity. ${ }^{16,29}$ This could be attributed to lethal congenital anomalies, ${ }^{16}$ low utero-placental perfusion caused by poor uterine vasculature in older women, chronic diseases such as diabetes and hypertension. 1,21,22,29 The same physiological explanations are valid for perinatal mortality ${ }^{9}$ in spite of conflicting evidence, ${ }^{11,12,15,29}$ as perinatal mortality seems to be ameliorated by both socioeconomic advantage and absence of chronic diseases. ${ }^{16,20,30}$

High BMI is considered an important predisposing factor towards the incidence of diabetes mellitus and gestational diabetes and hypertension. ${ }^{15,31}$ In our meta-analysis, chronic and gestational hypertension, pregestational and gestational diabetes were more frequent in the older age groups, which is in line with the majority of studies. 5,15,27,31-33 AMA is a risk factor for gestational diabetes, as pancreatic B-cell function and insulin sensitivity fall with age.9,16 Some authors blame these co-morbidities on adverse outcomes in older pregnant women. ${ }^{11,13}$ Notwithstanding, studies that only included low-risk pregnant women still found worse outcomes in the AMA group. As so, pre-existing disease does not fully explain adverse events associated with age. .,16

Older pregnant women are frequently labelled as 'higher risk' (even those without known risk factors) and such a generalization lowers the clinical threshold for obstetrical interventions, resulting in increased rates of CS for non-medical reasons. ${ }^{8,11,16,20}$ Two large studies ${ }^{34,35}$ still found higher CS rates after adjusting for several maternal characteristics (even though one of them was a meta-analysis including multiple pregnancy), ${ }^{34}$ suggesting AMA as a risk factor for caesarean birth and also hypothesizing a biological basis for these findings: poor progression and longer duration of labour with advancing age, impairment of myometrial contractility and dystocia are the most frequently discussed reasons. ${ }^{9,34,35}$

The higher rates of induced labour and elective CS among AMA women are likely to result from a combination
Odds ratio

M-H, fixed, $95 \% \mathrm{Cl}$

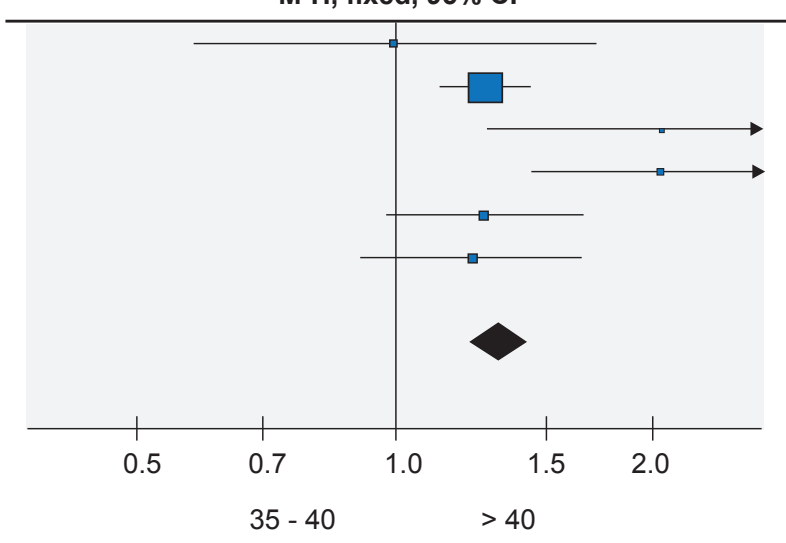

of physiological changes with maternal age and expressed physician and maternal preferences. ${ }^{36}$

Two studies ${ }^{16,37}$ support our findings on higher maternal death (MD) and maternal near miss (MNM) rates, and Balasch and Gratacós ${ }^{27}$ mention a strong tendency for increasing maternal mortality in older women in all developed countries. Risk factors for severe maternal morbidity and mortality are cardiovascular disease, diabetes, obesity and complications from operative deliveries. ${ }^{4,38}$

The risk of preterm birth increased with maternal age, which has previously been reported elsewhere, ${ }^{27,31,32,39,40}$ but some authors did not find a clear association between increased maternal age and risk of preterm birth. ${ }^{5,11,13,18}$ Furthermore, it remains unclear whether the correlation between AMA and prematurity is affected by socioeconomic factors. ${ }^{30,39}$ Ambiguous conclusions could be explained by definition of preterm delivery, differentiation between spontaneous preterm labour and iatrogenic preterm birth and baseline diseases. ${ }^{16,27}$ The consequences are an increased risk of perinatal morbidity and mortality and the need for higher intensity neonatal care. 5,29

A few small studies found no differences in BW among age groups. ${ }^{5,12,41}$ The correlation between AMA and low BW is seldom offset by socioeconomic factors and education levels. ${ }^{18,39,41-43}$ Instead, two physiological aspects may be more relevant: premature delivery and poor placental perfusion (due to a reduced cardiovascular reserve), both of which can result in low BW. ${ }^{16,39}$

In our meta-analysis, the lowest incidence of SGA babies was in the 35 - 40 age group. An accurate analysis of SGA neonates is hindered by variations in definition and conflicting literature: one study concluded that older primiparas, but not multiparas, were at an elevated risk for SGA offspring, ${ }^{29}$ whereas a retrospective cohort found no difference between $<40$ and $\geq 40$ YO age groups. ${ }^{15}$

The Apgar score is a good indicator of perinatal outcomes and a predictor of neonatal morbidity and neurological health. ${ }^{40,44} \mathrm{~A}$ recent study with low-risk primiparas reported that lower Apgar scores and NICU transfer occurred more often in operative deliveries. ${ }^{45}$ Heightened anxiety and 
lower threshold for transfer to NICU in older mothers have been proposed as a cause..$^{29,45}$

\section{Strengths and limitations}

Our studies were generally recent and very heterogeneous, being assessed in different low, medium and high income countries. This ensures a large, contemporary representation of the global population. Moreover, we included hospital and population-based studies, thus reducing the risk of bias selection.

We excluded studies that explicitly included women who used assisted reproductive technology (ART), but we did not exclude studies that did not report on natural versus artificial conception mode. We understand that retrospective studies may not contain information on conception mode and probably include women who undergo some type of infertility treatment. Nevertheless, knowing that the odds of more than one embryo being implanted are higher through artificial conception, we are automatically downsizing the ART population by excluding all multiple pregnancies. These limitations were hardly under our control and were therefore insuperable.

\section{CONCLUSION}

This meta-analysis suggests that AMA women are generally at a higher risk of adverse obstetrical and perinatal outcomes with increasing age; women aged 35 - 40 years had worse pregnancy outcomes than 20 - 34-year-olds and women $>40$ years had worse pregnancy outcomes than women aged 35 - 40 years.

\section{REFERENCES}

1. Waldenstrom U. Postponing parenthood to advanced age. Ups $\mathrm{J}$ Med Sci. 2016:1-9.

2. Laopaiboon M, Lumbiganon P, Intarut N, Mori R, Ganchimeg T, Vogel JP, et al. Advanced maternal age and pregnancy outcomes: a multicountry assessment. BJOG. 2014;121:S49-56.

3. Guedes M, Canavarro MC. Characteristics of primiparous women of advanced age and their partners: a homogenous or heterogenous group? Birth. 2014;41:46-55.

4. Sauer MV. Reproduction at an advanced maternal age and maternal health. Fertil Steril. 2015;103:1136-43.

5. Santos GH, Martins Mda G, Sousa Mda S, Batalha Sde J. Impacto da idade materna sobre os resultados perinatais e via de parto. Rev Bras Ginecol Obstet. 2009;31:326-34.

6. Muganyizi PS, Kidanto HL. Impact of change in maternal age composition on the incidence of Cesarean section and low birth weight: analysis of delivery records at a tertiary hospital in Tanzania, 1999-2005. BMC Pregnancy Childbirth. 2009;9:30.

7. Guo Y, Liu Y, He JR, Xia XY, Mo WJ, Wang P, et al. Changes in birth weight between 2002 and 2012 in Guangzhou, China. PLoS One. 2014;9:e115703

8. Cohen W. Does maternal age affect pregnancy outcome? BJOG. 2014;121:252-4

9. Orazulike NC, Jeremiah I, Green KI, Uzoigwe SA. Effect of age on childbearing in Port Harcourt, Nigeria. Int J Biomed Sci. 2015;11:82-5.

10. Ngowa JD, Ngassam AN, Dohbit JS, Nzedjom C, Kasia JM. Pregnancy outcome at advanced maternal age in a group of African women in two teaching hospitals in Yaounde, Cameroon. Pan Afr Med J. 2013;14:134.

11. Wang Y, Tanbo T, Abyholm T, Henriksen T. The impact of advanced maternal age and parity on obstetric and perinatal outcomes in singleton gestations. Arch Gynecol Obstet. 2011;284:31-7.

12. Ojule JD, Ibe VC, Fiebai PO. Pregnancy outcome in elderly primigravidae. Ann Afr Med. 2011;10:204-8.
In the broader literature, we found that some outcomes are the result of age-related comorbidities, while others are a consequence of aging itself and, therefore, unavoidable. Further outcomes could be attributed to healthcare professionals generally considering AMA as a high-risk pregnancy. In spite of better maternal education, social status, and medical follow-up, a higher risk persists with increasing age.

Older pregnant women should be individually assessed for their risk and besides informing women about the possible adverse outcomes that expectedly come with maternal age, health professionals should also provide appropriate management, which can be sought in specialized units for high risk pregnancies.

More investigation is needed in this area, as it becomes increasingly important to comprehend the pathophysiology behind adverse outcomes such as fetal morbimortality in older pregnant women. Further prospective studies that control numerous variables are also needed, to accompany the changing maternal demographics and to determine how comorbidities and life-style related factors can act as effect modifiers in obstetric and perinatal outcomes.

\section{CONFLICTS OF INTEREST}

All authors report no conflict of interest.

\section{FUNDING SOURCES}

This research received no specific grant from any funding agency in the public, commercial, or not-for-profit sectors.

13. Figueredo ED, Lamy Filho F, Lamy ZC, da Silva AA. Maternal age and adverse perinatal outcomes in a birth cohort (BRISA) from a Northeastern Brazilian city. Rev Bras Ginecol Obstet. 2014;36:562-8.

14. Benli AR, Cetin Benli N, Usta AT, Atakul T, Koroglu M. Effect of maternal age on pregnancy outcome and cesarean delivery rate. J Clin Med Res. 2015;7:97-102.

15. Chan BC, Lao TT. Effect of parity and advanced maternal age on obstetric outcome. Int J Gynaecol Obstet. 2008;102:237-41.

16. Usta IM, Nassar AH. Advanced maternal age. Part I: obstetric complications. Am J Perinatol. 2008;25:521-34.

17. Klemetti R, Gissler M, Sainio S, Hemminki E. At what age does the risk for adverse maternal and infant outcomes increase? Nationwide register-based study on first births in Finland in 2005-2014. Acta Obstet Gynecol Scand. 2016;95:1368-75.

18. Bakker R, Steegers EA, Biharie AA, Mackenbach JP, Hofman A, Jaddoe VW. Explaining differences in birth outcomes in relation to maternal age: the Generation R Study. BJOG. 2011;118:500-9.

19. Aldrighi JD, Wall ML, Souza SR, Cancela FZ. The experiences of pregnant women at an advanced maternal age: an integrative review. Rev Esc Enferm USP. 2016;50:512-21.

20. Li Y, Townend J, Rowe R, Knight M, Brocklehurst P, Hollowell J. The effect of maternal age and planned place of birth on intrapartum outcomes in healthy women with straightforward pregnancies: secondary analysis of the Birthplace national prospective cohort study. BMJ Open. 2014;4:e004026.

21. Montan S. Increased risk in the elderly parturient. Curr Opin Obstet Gynecol. 2007;19:110-2.

22. Huang L, Sauve R, Birkett N, Fergusson D, van Walraven C. Maternal age and risk of stillbirth: a systematic review. CMAJ. 2008;178:165-72.

23. Slim K, Nini E, Forestier D, Kwiatkowski F, Panis Y, Chipponi J. Methodological index for non-randomized studies (minors): development and validation of a new instrument. ANZ J Surg. 2003;73:712-6. 
24. Delpisheh A, Brabin L, Attia E, Brabin BJ. Pregnancy late in life: a hospital-based study of birth outcomes. J Womens Health. 2008;17:96570.

25. Pattinson R, Say L, Souza JP, van den Broek N, Rooney C. WHO maternal death and near-miss classifications. Bull World Health Organ. 2009;87:734

26. Moher D, Liberati A, Tetzlaff J, Altman DG. Preferred reporting items for systematic reviews and meta-analyses: the PRISMA statement. BMJ. 2009;339:b2535.

27. Balasch J, Gratacos E. Delayed childbearing: effects on fertility and the outcome of pregnancy. Curr Opin Obstet Gynecol. 2012;24:187-93.

28. Page JM, Snowden JM, Cheng YW, Doss AE, Rosenstein MG, Caughey $A B$. The risk of stillbirth and infant death by each additional week of expectant management stratified by maternal age. Am J Obstet Gynecol. 2013;209:375.e1-7.

29. Lisonkova S, Janssen PA, Sheps SB, Lee SK, Dahlgren L. The effect of maternal age on adverse birth outcomes: does parity matter? J Obstet Gynaecol Can. 2010;32:541-8.

30. Carolan M, Frankowska D. Advanced maternal age and adverse perinatal outcome: a review of the evidence. Midwifery. 2011;27:793801.

31. Luke B, Brown MB. Elevated risks of pregnancy complications and adverse outcomes with increasing maternal age. Hum Reprod. 2007;22:1264-72.

32. Ludford I, Scheil W, Tucker G, Grivell R. Pregnancy outcomes for nulliparous women of advanced maternal age in South Australia, 19982008. Aust N Z J Obstet Gynaecol. 2012;52:235-41.

33. Yoshioka-Maeda K, Ota E, Ganchimeg T, Kuroda M, Mori R. Cesarean section by maternal age group among singleton deliveries and primiparous Japanese women: a secondary analysis of the WHO Global Survey on Maternal and Perinatal Health. BMC Pregnancy Childbirth. 2016;16:39.

34. Bayrampour H, Heaman M. Advanced maternal age and the risk of cesarean birth: a systematic review. Birth. 2010;37:219-26.

35. Smith GC, Cordeaux Y, White IR, Pasupathy D, Missfelder-Lobos H, Pell $\mathrm{JP}$, et al. The effect of delaying childbirth on primary cesarean section rates. PLOS Med. 2008;5:e144.

36. Zizzo AR, Kirkegaard I, Pinborg A, Ulbjerg N. Decline in stillbirths and perinatal mortality after implementation of a more aggressive induction policy in post-date pregnancies: a nationwide register study. Acta Obstet Gynecol Scand. 2017;96:862-7.

37. Donoso E, Carvajal JA, Vera C, Poblete JA. La edad de la mujer como factor de riesgo de mortalidad materna, fetal, neonatal e infantil. Rev Med Chil. 2014;142:168-74.

38. Oliveira FC Jr., Surita FG, Pinto ES, Cecatti JG, Parpinelli MA, Haddad $\mathrm{SM}$, et al. Severe maternal morbidity and maternal near miss in the extremes of reproductive age: results from a national cross- sectional multicenter study. BMC Pregnancy Childbirth. 2014;14:77.

39. Restrepo-Mendez MC, Lawlor DA, Horta BL, Matijasevich A, Santos IS, Menezes AM, et al. The association of maternal age with birthweight and gestational age: a cross-cohort comparison. Paediatr Perinat Epidemiol. 2015;29:31-40.

40. Gravena AA, Sass A, Marcon SS, Pelloso SM. Outcomes in late-age pregnancies. Rev Esc Enferm USP. 2012;46:15-21.

41. Ahmadu BU, Mustapha B, Bappariya JI, Alfred N, Joel Z. The effects of weathering demonstrated by maternal age on low birth weight outcome in babies. Ethiop J Health Sci. 2013;23:27-31.

42. Swamy GK, Edwards S, Gelfand A, James SA, Miranda ML. Maternal age, birth order, and race: differential effects on birthweight. J Epidemiol Community Health. 2012;66:136-42.

43. Weng YH, Yang CY, Chiu YW. Risk assessment of adverse birth outcomes in relation to Mmaternal age. PLOS One. 2014;9:e114843.

44. Almeida NK, Almeida RM, Pedreira CE. Adverse perinatal outcomes for advanced maternal age: a cross-sectional study of Brazilian births. J Pediatr. 2015;91:493-8

45. Herstad L, Klungsoyr K, Skjaerven R, Tanbo T, Forsen L, Abyholm $\mathrm{T}$, et al. Elective cesarean section or not? Maternal age and risk of adverse outcomes at term: a population-based registry study of low-risk primiparous women. BMC Pregnancy Childbirth. 2016;16:230.

46. Blomberg $M$, Birch Tyrberg R, Kjolhede P. Impact of maternal age on obstetric and neonatal outcome with emphasis on primiparous adolescents and older women: a Swedish Medical Birth Register Study. BMJ Open. 2014;4:e005840.

47. Kenny LC, Lavender T, McNamee R, O'Neill SM, Mills T, Khashan AS. Advanced maternal age and adverse pregnancy outcome: evidence from a large contemporary cohort. PLOS One. 2013;8:e56583.

48. Mutz-Dehbalaie I, Scheier M, Jerabek-Klestil S, Brantner C, Windbichler $\mathrm{GH}$, Leitner $\mathrm{H}$, et al. Perinatal mortality and advanced maternal age. Gynecol Obstet Invest. 2014;77:50-7.

49. Pasupathy D, Wood AM, Pell JP, Fleming M, Smith GC. Advanced maternal age and the risk of perinatal death due to intrapartum anoxia at term. J Epidemiol Community Health. 2011;65:241-5.

50. Richards MK, Flanagan MR, Littman AJ, Burke AK, Callegari LS. Primary cesarean section and adverse delivery outcomes among women of very advanced maternal age. J Perinatol. 2016;36:272-7.

51. Timofeev J, Reddy UM, Huang CC, Driggers RW, Landy HJ, Laughon SK. Obstetric complications, neonatal morbidity, and indications for cesarean delivery by maternal age. Obstet Gynecol. 2013;122:1184-95.

52. Waldenstrom U, Aasheim V, Nilsen AB, Rasmussen $S$, Pettersson $H J$, Schytt E. Adverse pregnancy outcomes related to advanced maternal age compared with smoking and being overweight. Obstet Gynecol. 2014;123:104-12 